\title{
La épica de los Jesuitas: juicios y comentarios sobre El Bernardo, de Balbuena
}

The epic of Jesuits: judgement and comments to Balbuena's El Bernardo

Claudia García-Minguillán Universidad de Salamanca / IEMYRhd

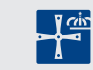




\section{RESUMEN}

A partir de la segunda mitad del siglo XVIII, España necesita más que nunca demostrar al resto de naciones europeas la calidad de su literatura. Se persigue por distintas vías recuperar textos canónicos que puedan aportar una imagen de valor nacional, y una de estas vías es la consideración del género épico. En este trabajo analizamos la labor de Juan Francisco Masdeu, jesuita expulso, que, junto a otros miembros de la Compañía, recuperó la figura de Bernardo de Balbuena y su poema heroico El Bernardo o Victoria de Roncesvalles (1624) para proponerlo ante Europa como el Tasso español.

Palabras clave

Poesía épica, jesuitas, Bernardo de Balbuena, El Bernardo, Juan Francisco Masdeu.

\section{ABSTRACT}

Since the second half of the XVIII century, Spain needed to demonstrate the rest of European nations the quality of its literature. They tried in different ways to recover canonic texts that could show an image of national value. One of these ways was, for instance, the assessment of the epic genre. In this essay, we analyze the aim of Juan Francisco Masdeu, expelled Jesuit, who, with other members of the Company, recovered the figure of Bernardo de Balbuena and his heroic poem El Bernardo o Victoria de Roncesvalles (1624) with the objective of proposing Balbuena as the Spanish version of Tasso.

KeY WORDS

Epic poetry, Jesuits, Bernardo de Balbuena, El Bernardo, Juan Francisco Masdeu.

Recibido: 16 de mayo de 2018. Aceptado: 30 de julio de 2018.

Este trabajo se inscribe en el marco del proyecto de investigación Teoría de la lectura y hermenéutica literaria en la Ilustración: edición de fuentes documentales y literarias (1750-1808) (FFI2016-80168-P) del Ministerio de Economía y Competitividad. 
En una conferencia leída a finales del año de 1941 en el Ateneo Barcelonés, Batllori ${ }^{1}$ mencionaba el valor de los jesuitas expulsados por Carlos III ${ }^{2}$. Denominándolos por el término «literatos», el erudito dirigía su discurso hacia la capacidad del término para sumergirnos en pleno siglo XVIII ${ }^{3}$, relacionando la esencia del siglo con las labores de este grupo. El trabajo filológico que desarrollaron en las últimas décadas del siglo abarcó diversas escalas, desde la magnitud de proyectos sobre la historia de la cultura y la literatura, hasta trabajos de escala más reducida como la recuperación y el análisis de textos.

El poema épico del obispo Balbuena, El Bernardo o Victoria de Roncesvalles (1624) fue uno de estos textos estudiados, analizados y recuperados por los miembros de la Compañía, y pasó de no haber sido apenas considerado en su tiempo a ser propuesto como el representante de la épica española.

Esta, en apariencia, contradictoria situación nos lleva a analizar si bien fue el cambio del gusto de la época o bien la situación histórica la que favoreció el protagonismo del Bernardo. Asimismo, un breve acercamiento a los comentarios de este grupo nos hace formular la posibilidad de identificar una estética jesuítica para el género épico.

Antes de la materia dieciochesca: El Bernardo de Balbuena y su circunstancia

El Bernardo o Victoria de Roncesvalles es un poema épico escrito en las tierras de la Nueva España en el último decenio del siglo Xvi. Tradicionalmente considerado como un texto colonial, su materia no concentra los elementos típicos que albergan los textos fundacionales de este género como Los actos y hazañas valerosas (1564) de Pedro de la Cadena o La Araucana (1569, 1578,

1 Miguel BatLloRI, «La irrupción de los jesuitas españoles en la Italia dieciochesca», Razón y Fe, 126 (1942), págs. 108-130.

2 Sobre esta esfera de jesuitas, centrado en la figura de Juan Andrés, tenemos la aportación de Franco Quinziano, «Un capitolo nei rapporti ispano-italiani nel Settecento. Enciclopedismo, sincretismo e dialogo culturale nel jesuita espulso Juan Andrés» Artifara, 16 (2016), págs. 27-45.

3 Para entender lo acertado de este término, véase Pedro Áldarez DE miRanda, Palabras e ideas: el léxico de la Ilustración temprana en España (1680-1760), Madrid, Real Academia Española, 1992, págs. 441-447. 
1589) de Ercilla. El tema principal del poema es el mito histórico de Bernardo del Carpio y, de la misma manera que Ariosto en su Orlando, Balbuena introduce secuencias paralelas a la historia principal, que narran las hazañas nacionales y la conquista del Nuevo Mundo.

Tanto del empleo de crónicas medievales para documentar los mitos fundacionales de Castilla como de la influencia de la producción épica del ciclo cortesiano $^{4}$, surge una epopeya que combina el imaginario medieval castellano con el imaginario de Indias. Esta combinación, aunque poco usual, es el resultado de un espacio de creación novohispano en el que la convivencia de criollos, mestizos e inmigrantes peninsulares generó precisamente un intercambio y cohesión culturales. El marco de la simbología endémica que generaron los primeros conquistadores, transmitiéndola al Viejo Mundo a través de las crónicas y los poemas épicos, se adhiere a la materia castellana como un sustrato de esta.

Las obras Grandeza Mexicana (México, 1604), Siglo de oro en las selvas de Erifile (Madrid, 1609) y El Bernardo o victoria de Roncesvalles (Madrid, 1624) forman el corpus poético de Bernardo de Balbuena ${ }^{5}$. El poema heroico fue sin duda su gran proyecto, pero, por a una serie de eventos que nos alejarían del propósito de nuestro trabajo, el texto sufrió distintas fases de composición y publicación, retrasándose hasta quince años su definitiva impresión. Debido a este hecho, la fama esperada del Bernardo se quedó en poco menos que en una mera anécdota y habrá que esperar unos años para advertir de nuevo la presencia de Balbuena en la historia literaria.

\section{Desde la transmisión hacia el canon}

La idea general de que El Bernardo fue y es hoy día un texto desconocido y que apenas ha sido leído parece fundada en una perspectiva en apariencia correcta, aunque desprecia algunos matices. Si bien es cierto que el gusto

\footnotetext{
4 Conjunto de poemas épicos coloniales que dedican su materia poética a la figura de Hernán Cortés y la conquista de México: Cortés valeroso (1588) y Mexicana $(1588,1594)$ de Gabriel Lobo Lasso de la Vega, Peregrino Indiano (1599) de Saavedra Guzmán.

5 Se sabe que fue natural de Valdepeñas y descendiente de colonos de las tierras de la Nueva España, lugar al que se dirigió apenas cumplidos veinte años. Allí obtuvo su educación superior como bachiller en teología y cánones para, finalmente, ordenarse como sacerdote. Combinó esta labor con la de poeta y persiguió el reconocimiento de sus méritos para conseguir una mejor posición social al participar de manera activa con sus obras en el debate criollo a favor de los descendientes de inmigrantes peninsulares. Para más información, véase Jorge L. Terukina, El imperio de la virtud: Grandeza Mexicana (1604) de Bernardo de Balbuena y el discurso criollo novohispano, Londres, Támesis, 2017.
} 
de la antesala a nuestro Siglo de Oro se tornaba más hacia el teatro y los espacios de la comedia, el género épico tuvo un público muy seleccionado a la que vez que fiel. Es justo como indica Chevalier ${ }^{6}$ cuando identifica a los lectores de épica culta, género que no iba dirigido al espectador de los corrales de comedia sino a una élite cultural, cercana a la corte y a la política del momento.

Entre los poetas coetáneos, Balbuena fue alabado en boca de Luis Belmonte Bermúdez, autor del poema épico La Hispálica (c. 1600-1619), Saavedra de Guzmán, autor de Peregrino Indiano (1599), alaba al autor con un soneto preliminar a Grandeza Mexicana, Lope de Vega y Quevedo aportan su participación sonetista a los preliminares del Siglo de Oro, resonando en la del Fénix la presencia del poema épico ${ }^{7}$. Goza también Balbuena del favor de Mira de Amescua, quien se hace cargo de la censura de la primera versión del Bernardo en $1609^{8}$. Tres años después de la muerte del autor, Lope le alaba en su Laurel de Apolo (1630), recogiendo de nuevo una mención al Bernardo ${ }^{9}$. Entre los posibles lectores de este texto, contamos con el Conde de Lemos que fue incluso posible anotador y comentador del poema ${ }^{10}$.

Cultivadores del género épico, importantes poetas y miembros de la corte alta fueron los receptores de esta epopeya ${ }^{11}$ y, aun así, Nicolás Antonio lamentaba en su Bibliotheca hispana-nova (1670) la escasa y pobre recepción:

cuando en realidad ella se alza incontinente con la majestad del poema, deleite con la invención y variedad de los episodios, a ningún otro cede en brillantez y pureza

6 Maxime Chevalier, Lectura y lectores en la España del siglo XVI y XVII, Madrid, Turner, 1976.

7 Estos versos indican que en la comidilla de poetas ya se conocía El Bernardo: «Emuló a Italia, al mismo honor aspira/Bernardo y a las selvas lisonjero/mientras le llama al son de Marte fiero/ dulces versos de amor canta y suspira», Bernardo de Balbuena, El Siglo de Oro en las selvas de Erifile, Madrid, Alonso Martín, 1608, f. 4 r.

8 La aprobación firmada por Mira de Amescua en 1609 es la que se mantiene en los preliminares de la edición impresa en 1624. Se conoce una primera versión del poema en formato manuscrito (Fundación Menéndez Pidal) que sería la empleada para realizar la aprobación de 1609. La versión que ha llegado hasta la actualidad-en formato impreso, con fecha de 1624, presenta cambios con esa primera versión.

9 Lope de Vega y Carpio, Laurel de Apolo, ed. de Antonio Carreño, Madrid, Cátedra, 2007, págs. 192-193.

10 «Este poema heroico [...] se le dedicó su autor [...] al gran mecenas Pedro Fernández de Castro [...]con la agradable benignidad de su nobilísima condición no se desdeñó a honrar la obra, pasando los ojos por ella, debajo de la aprobación de su clarísimo ingenio, se ganó privilegio para imprimirla», Bernardo de Balbuena, El Bernardo o Victoria de Roncesvalles, Madrid, Diego Flamenco, 1624, f. 4r.

11 El mismo Balbuena insiste en este elitismo: «¿Si ha de acabarse aquí en el primer vuelo o ha de volar sin fin de gente en gente? / ¿Si subió el ave mi papel al cielo/o caer le dejó de impertinente? / ¿Quién me dirá esta enigma? ¿Este recelo, /a quién no hace encoger hombros y frente? / El tiempo lo hará claro y mi motivo, / los sabios, que es el pueblo a quien escribo» (Bernardo de BalbuEna, El Bernardo o Victoria de Roncesvalles, f. 236v). 
de lenguaje, y deja en mi opinión, por el empleo de apropiadísimas comparaciones, atrás y con mucho, dicho sea brevemente, a todos nuestros poetas ${ }^{12}$.

Atender a la situación y a los posibles motivos de la escasa recepción del Bernardo en su siglo nos lleva por unos derroteros que nos desviarían del objetivo de este trabajo: la verdadera transmisión del texto. Fue a finales del siglo XVIII cuando el poema encontró un espacio que atendió a su materia y le dio sentido. A continuación, centraremos nuestra línea de investigación en este contexto de recepción centrado en dos territorios: España e Italia, separados geográficamente y sin embargo unidos por el traslado de los miembros de la Compañía ignaciana, los cuales hicieron florecer la defensa de las letras hispanas frente a Europa y, recuperando este carácter humanista que recordamos, recobraron la memoria de algunos textos, entre ellos, El Bernardo de Balbuena.

\section{La defensa de nuestra literatura en la «colonia jesuítica»}

El conflictivo año de 1782, reconocido como el inicio de nuestro belicismo intelectual, tuvo como enemigo central la crítica del país galo y, a modo de metonimia, la batalla se libró contra el enciclopedista Masson de Morvilliers, desafortunado autor del archiconocido artículo sobre España, en el que, con la poca elegancia esperada, clamaba infamando «¿Qué le debe Europa a España?» (Encyclopédie methódique, 1782).

Esta crítica, sin embargo, no debió generar demasiada sorpresa, puesto que se posicionaba en sintonía con recriminaciones anteriores de intelectuales coetáneos europeos, de la talla de Voltaire o Montesquieu. Desde su relativo protagonismo en la historia moderna occidental, España fue el centro de ataques y ofensivas por parte de las naciones vecinas. Y, durante el siglo XVIII, a pesar del aire derrotista frente a las nuevas potencias, siguió recibiendo atribuciones a favor de la conocida como Leyenda Negra y contrarias a reconocer el prestigio de España en el progreso cultural. Como indica lúcidamente François Lopez ${ }^{13}$, las reacciones no mostraban una inquietud por la argumentación de escaso crédito de Morvilliers, sino, más bien, la preocupación por el soporte, en apariencia

\footnotetext{
12 Nicolás Antonio, Biblioteca Hispana Nueva, o de los escritores españoles que brillaron desde el año MD hasta el de MDCLXXXIV, trad. y ed. de Miguel Matilla Martínez, Madrid, Fundación Universitaria Española, 1999, pág. 227.

13 François Lopez, Juan Pablo Forner y la crisis de la conciencia española en el siglo XVII, Salamanca, Junta de Castilla y León, 1999, pág. 340.
} 
metódico y llevado por la razón donde no debían entrar exacerbados juicios irracionales, en el que quedaba reflejada esa imagen de España.

La respuesta de la Real Academia Española fue convocar un certamen para producir, bajo el lema de la defensa de la nación, una apología de España en materia de progreso en ciencia y arte, pero no fue más que un mero adorno — ni siquiera hubo ganador- en comparación al enfrentamiento dialéctico que se había producido con anterioridad ${ }^{14}$.

Para ello, nos debemos remontar a 1768, año en que España propuso un Parnaso español, lugar en el que aparece citado Balbuena. Sus principios y fuentes fueron «exceder a los modernos de las naciones vivas» $\mathrm{y}$ «competir con los antiguos de Grecia y Roma» ${ }^{15}$, pero sus lectores fueron «los amantes de las glorias de la nación». En conclusión, aun siendo una obra de gran valor para el país, careció de carácter y no intuyó la idea que el resto de países tenían de España.

Porque menos de cuatro años le bastaron al abate Tiraboschi, polemista de la Compañía ignaciana, para comenzar un proyecto parnasista bajo el tímido título de Storia della letteratura italiana (1772-1782) aunque no era solo una historia literaria. En ella Tiraboschi afirmaba sin tapujos que el declive de la literatura romana fue causado por autores ibéricos, «corruptores de la elocuencia», Séneca, Marcial y Lucano, discurso compuesto por otros argumentos que generaron un efecto dominó. El siguiente eslabón, Saverio Bettinelli, también polemista y amigo de Tiraboschi, acusó a los españoles de embarrar de «cattivo gusto» la poesía del siglo XVII e identificó a los escritores árabes instalados en la Península ibérica como «barbari corrompitori della ragione» ${ }^{16}$. Todo esto en su Risorgimento d'Italia negli studi, nelle arti e ne' costumi dopo il Mile (1775). Para completar el triunvirato ${ }^{17}$ nos falta Pietro Napoli Signorelli, cuya mirada

14 Para profundizar en los certámenes de la RAE, acúdase el trabajo de M. José RodríGuez SÁnchez DE LEón, «Los premios de la Academia Española en el siglo XVII y la estética de la época», Boletín de la Real Academia Española, tomo LXVII, cuaderno CCXLII (1987), págs. 395-425.

15 López Sedano, Parnaso español. Colección de poesías escogidas de los más célebres poetas castellanos, Madrid, Joaquín Ibarra, tomo I, pág. I.

16 Saverio Bettinelu, Risorgimento d'Italia negli studi, nelle arti e ne' costumi dopo il Mile, Basano, Remondini di Venezia, 1786, pág. 129.

17 El enfrentamiento dialéctico entre estos intelectuales queda recogido en Francisco AGUILAR PIÑAL, Historia literaria de España en el siglo XVIII, Madrid, Trotta / Consejo Superior de Investigaciones Científicas, 1996, pág. 536, además de Miguel Batllori, La cultura hispano-italiana de los jesuitas expulsos. EspañolesHispanoamericanos-Filipinos. 1767-1814, Madrid, Gredos, 1966, págs. 38-41. Para un enfoque más específico, véanse los trabajos de Wido Hempel, «Per la storia delle polemiche fra Bettinelli, Tiraboschi, Napoli Signorelli e i gesuiti spagnuoli», en VV. AA., Problemi di lingua e letterature italiana del Settecento, IV Congresso dell'Associazione Internazionale per gli studi di Lingue e letterature italiana, Wiesbaden, Steiner, 1965, págs. 115-120; y Manfred Tıtz, «Die Polemik um die spanische Literatur im 18. Jahrhundert: der Streit zwischen Tiraboschi, Bettinelli und Llampillas», en Gerhard Schmidt y Manfred Tietz (eds.), Stimmen der Romania, Wiesbaden, Festschrift fur W. Theodor Elwert, 1980, págs. 429-449. 
crítica recalcó la superioridad del drama italiano sobre el teatro español, dejando a nuestros Lope, Tirso y Calderón sin defensa posible sobre las páginas de su Storia critica dei teatri antichi e moderni (1777).

En respuesta a esta última publicación surgen contra «le pregiudicate opinioni di alcuni moderni scrittori italiani» y en defensa de la cultura e idea de España, las figuras de Xavier Lampillas y Juan Francisco Masdeu, literatos y jesuitas expulsos en Italia. El primero responde:

Instruido por estos sabios documentos dictados no menos por la buena moral que por el buen gusto, protesto escribir esta apología contra las preocupadas opiniones, que en descredito de la literatura de los españoles muestran abrigar en su seno los señores abates Geronimo Tiraboschi y Xavier Bettinelli ${ }^{18}$.

Y a esto, el jesuita no cae solo en el discurso apologético, forzosamente vacuo debido a lo hiperbólico de sus típicos agentes, sino que procura «luz a la literatura española, defendiendo a nuestros escritores de quien preocupado contra su mérito ha ofuscado no poco su gloria» ${ }^{19}$.

Con este enfrentamiento dialéctico, la defensa de la nación se vio realizada antes en Italia que en la propia España. En esta «colonia jesuítica», como la llega a denominar en algún lugar Cascón ${ }^{20}$, se produjo aquel fenómeno de extremado valor cultural. Y el testigo lo recogió Juan Francisco Masdeu, quién mejor, pues su brío y prolijidad así respondían a las posibles fisuras de su discurso: «Ya sabía yo que Montesquieu es un santo padre, contra quien no se puede abrir la boca sin cometer un delito gravísimo ${ }^{21}$. El problema surgió de Juan Ristori quien, en la censura del tomo preliminar a la Historia crítica de España y de la cultura española (1783) de Masdeu, dijo:

En otro lugar de estas memorias notamos, que Muratori, Quadrio, Crescimeni y Nisieli no supieron hacer un verso bueno, y que Homero, Virgilio, Tasso, Voltaire y Milton jamás conocieron los preceptos. Pero los poetas españoles han

18 Xavier Lampillas, Ensayo historico-apologético de la literatura española contra las opiniones preocupadas de algunos escritores modernos italianos. Disertaciones del señor abate don Xavier Lampillas. Parte primera de la literatura antigua. Tomo primero. Traducido del italiano al español por doña Josefa Amar y Borbón, residente en la ciudad de Zaragoza. Con licencia y privilegio. En Zaragoza, en la oficina de Blas Miedes, impresor de la Real Sociedad, año de 1782, pág. 2.

19 Lampillas, Ensayo historico-apologético de la literatura española, pág. 4.

20 P. M. Cascón, «La emigración de los Jesuitas españoles en el Siglo XVIII y el Renacimiento de los estudios humanistas en Italia», Anuario cultural italo-español, vol. I (1941), págs. 37-69; pág. 38.

${ }^{21}$ Juan Francisco Masdeu, Historia crítica de España y de la cultura española, Madrid, Imprenta de Sancha, 1783, pág. 295 
faltado a la verisimilitud, se han valido de falsos colores, y muchas veces en sus obras han copiado aquel monstruo caprichoso que describe Horacio en el principio del arte poética ${ }^{22}$.

Ristori no le dio otra opción a Masdeu más que recriminarle con su mejor arma, la virtud de la retórica:

¿De quién aprendisteis que los poetas no deben obedecer a ningún precepto? No os atrevéis a decirlo por los motivos que sabéis. Yo lo diré. Lo aprendisteis de Voltaire, que es quien ha promovido esta herejía literaria. Vuestras expresiones son las mismas de aquel escritor. Decís como él, que Homero, Virgilio, Tasso y Milton nunca supieron los preceptos. Doy el parabién a Voltaire y a vos por haber llegado a ser especuladores del interno de aquellos poetas ${ }^{23}$.

Por todo ello incidimos en el año de 1783, año de publicación de la Historia crítica de Masdeu que hizo más - y a tiempo — por la defensa de España que el certamen de la Real Academia Española convocado dos años más tarde. En dicha obra, responde a su censor con palabras que igual valieron para el resto de intelectuales: «iCuando habréis sanado perfectamente, me agradeceréis los esfuerzos que he hecho en favor más de vuestra nación que de la mía; porque verdaderamente la ignorancia en que está la Italia de las cosas de España no es deshonor de los españoles sino de los italianos!» ${ }^{24}$.

Y los grandes esfuerzos del jesuita para paliar la ignorancia de la Italia trataron precisamente de hacer llegar la cultura española al país vecino, no solo a través de su Historia crítica, sino a partir de una selección de grandes poetas españoles publicada en Italia a la vez que con la traducción y proyectos de impresión de grandes textos de España. Fue debido a este fenómeno cultural por el cual se recuperó la figura de Bernardo de Balbuena y, en especial, como revela el profesor Cátedra ${ }^{25}$, el proyecto de reimpresión de su poema heroico.

22 Juan Ristori Florentin, «Censura del tomo preliminar de la Historia crítica de España. Publicada por el doctor Juan Ristori Florentin en el folio xxx de las Memorias Enciclopédicas de Bolonia del 1781» en Juan Francisco Masdeu, Historia crítica de España y de la cultura española, pág. 285

${ }_{23}$ Juan Francisco Masdeu, Historia crítica de España y de la cultura española, pág. 306

24 Masdeu, Historia crítica de España y de la cultura española, pág. 294.

25 Pedro M. Cátedra, G. B. Bodoni. Del silencio ibérico a «La Comedia Nueva» (1796), Salamanca, Ediciones Universidad de Salamanca, 2013, pág. 123. 


\section{¿Cómo se interpreta la épica?: Balbuena en el Parnaso}

El abate Masdeu sabía muy bien a qué aspiraba y cómo enfrentaba sus objetivos. Él mismo reconoce que debió, primero, defender «largamente a los poetas de mi nación de los sobredichos defectos que se les suelen atribuir» ${ }^{26}$. Todos conocemos la pompa de los discursos apologéticos, como hemos dicho antes, a veces tan vacuos e hiperbólicos que generan en el lector una desidia muy alejada del interés por lo que se está leyendo. Por esta misma razón, el jesuita cree dar con la clave: acercar nuestros clásicos al paladar italiano.

Mas creo que la mejor defensa es la de presentarlos en traje italiano, para que la Italia los lea, y los conozca. Los italianos no hallarán en las poesías comprendidas en estos tomos, como tampoco en las que podré publicar en adelante en mucho mayor número, ni imaginaciones locas, ni hinchazón en las frases, ni falsedad en los pensamientos. Antes bien, encontrarán una noble simplicidad, y una delicadeza admirable: encontrarán pensamientos grandes e ingeniosos, expresiones nobles y justas, invenciones hermosas y bien dispuestas ${ }^{27}$.

Muy a pesar de que Masdeu presentase la obra con el «dar a la Italia un Parnaso Español $»^{28}$, este mausoleo de 22 deidades no presentó la flaqueza de aquel de Sedano, debido a que la transmisión y valor de este no tuvo parangón alguno con la naturaleza declaratoria del otro, asentado y construido en Roma, escrito en lengua extranjera y bien presentado al gusto italiano. Deducimos, pues, el grave esfuerzo de ver trinchada nuestra literatura y seleccionar a duras, durísimas penas, una leve huella de patrimonio. A pesar de la flacura, no echamos en falta en los Parnasos un rastro de poesía heroica y su presencia es un signo indicativo.

Este elemento queda revelado frente al pronóstico de la escasa repercusión, la irrisoria transmisión de la obra, y el lamento de Nicolás Antonio, porque la figura de Bernardo de Balbuena resurge entre Argensola y Boscán en el Parnaso de Masdeu, y como él mismo nos indica, fue «uno de los mejores poetas castellanos del buen siglo, a cuyo mérito no ha correspondido la fama, ni el concepto que suelen tener de él los mismos españoles» ${ }^{29}$.

A este nuevo parnaso no le bastó con la mera alabanza. Todo lo contrario, persiguió igualar en condiciones la justa por la superioridad literaria. Y aquí

${ }_{26}$ Juan Francisco Maspeu, Poesie di ventidue autori spagnuoli del cinquecento, tomo I, Roma, Salvioni, 1786, pág. 16.

27 Masdeu, Poesie di ventidue autori spagnuoli del cinquecento, pág. 16.

28 Masdeu, Poesie di ventidue autori spagnuoli del cinquecento, pág. 18.

29 Masdeu, Poesie di ventidue autori spagnuoli del cinquecento, pág. 30. 
es donde entra la dialéctica, la superposición de textos y glorias nacionales, $E l$ Bernardo, texto en apariencia desconocido, compite con el Tasso: «El Bernardo o Victoria de Roncesvalles, poema épico en veinte y cuatro cantos, el mejor tal vez que se haya hecho en lengua castellana, y capaz de competir con la Jerusalen del Tasso» ${ }^{30}$. Una vez conocidos los objetivos y medios del jesuita, resulta fácil deducir por qué derroteros saldría su siguiente estrategia. Puede resultar difícil, sin embargo, pensar en alguna táctica mejor para acercar nuestros clásicos. Nuestro abate Masdeu, a pesar de lo conseguido, recalcó una vez más en su ingenio y valía.

Por el mismo año en el que se publicaba la Oración apologética de Forner ${ }^{31}$ - 1785 - todo lo anterior estaba sucediendo ya en Italia. Hablamos de un proceso de documentación, de corte claramente humanista, que nos recuerda a la escena de Petrarca descubriendo a un Cicerón. Cómo mejor se revive a un clásico, si no es dándole un formato fresco y agradable a la vista, además de la traducción a lengua extranjera, para adaptarlo a los nuevos tiempos. Bien era esto sabido por nuestros literatos expulsos, especialmente uno entre ellos, Diosdado Caballero, el mismo que unos años más tarde, persigue espolear los rodamientos de Parma con una carta al famoso impresor:

Sopra tutto, io metterei mano, per essere più a seconda del genio degli spagnoli a la stampa dell'opere di Bernardo Balbuena, poeta maraviglioso, di cui abbiamo diverse produzioni già rarissime d'squisitissimo [sic] gusto, come il poema epico intitolato il Bernardo, ovvero Derrota de Roncesvalles, per cui la Spagna non ha perché invidiare nessuna altra nazione [...] La stampa bodoniana così magnifica ed elegante di questo autore sarebbe un gran servizio, per non dire adulazione, che potrebbe farsi alla nazione spagnola e la maggior testimonianza dell'attacamento vostro per essa [...] la stampa dell'autore spagnolo interessarebbe tutta la Nazione, e restarebbe la medesima convinta come il divino typografo Bodoni pretendeva lasciare per mezzo di essa a viventi ed a posteri un monumento luminosissimo che attesti la munificenza del Monarca spagnolo ${ }^{32}$.

$30 \quad$ Masdeu, Poesie di ventidue autori spagnuoli del cinquecento, pág. 32.

31 Jesús Cañas Murillo ha realizado diversos trabajos sobre Forner, entre ellos traigo a colación «Autoridad y autoridades en la Oración apologética de Forner», en Jesús Cañas Murillo y Miguel Ángel Lama (eds.), Juan Pablo Forner y su época (1756-1797), Mérida, Editora Regional de Extremadura, 1998, págs. 303-378. Para profundizar sobre la personalidad apologista y política de Forner, remito al clásico trabajo de LoPEz, Juan Pablo Forner y la crisis de la conciencia española en el siglo XVIII, en especial el capítulo IV, muy relacionado con nuestro tema, «Forner, apologista de España», págs. 311-428.

32 Carta de Raimundo Diosdado Caballero a Giambattista Bodoni de 1793-12-04, ed. Pedro M. Cátedra, en Biblioteca Bodoni [http://bibliotecabodoni.net/carta/1793-12-04-diosdado-bodoni (Consulta: 18/04/2018]. 
El lector advierte en seguida que la insistencia de Diosdado Caballero por aquel texto no es sino un favor al amigo Masdeu, además de comulgar con su habilidad de «ágil constructor» de la idea de la nación española ${ }^{33}$. Y no es el primero, puesto que ya estaba en plena colaboración cuando en las noticias de la biografía de Balbuena, Masdeu dice deber aquella información a su «amigo D. Ramón Diosdado español de mucha literatura, que las ha buscado aquí en Roma del modo que ha podido ${ }^{34}$. Esto fue en 1786. Desconocemos por el momento en qué lugar de la actividad de Caballero ${ }^{35}$ quedó dicho proyecto, pero, sin llegar a tardar más de seis años, El Bernardo era ya una realidad en las mentes de, al menos, estos dos jesuitas, y parece ser que desde España también se deseaba ver construido este monumento a la nación:

Si potrebbe aggettare che la stampa del Balbuena -la più cara e desiderata dagli spagnoli e la più utile per lo stampatore- non puol essere introdotta in Spagna. Ma voi, Signore, siete typografo spagnolo, onde la proibizione non vi coglie, oltradicché la straordinaria nobiltà della vostra stampa renderà facile la licenza del governo per questa giustissima eccezione verso di voi ${ }^{36}$.

Pero no fue la voluntad del principe dei tipografi, Giambattista Bodoni. Quizás por el compromiso demasiado gravoso o por el deseo de esperar unos tiempos menos turbulentos, el proyecto, desgraciadamente, no vio la luz. La decisión quedó plasmada en una ambigua respuesta — non accetto ne ricuso— donde el impresor explica su postura:

Per ora io non accetto ne ricuso la di Lei offerta, e mi riservo di farne laudevol uso qualora sarò sciolto dell' impegno in cui trovomi attualmente ingolfato, non ostante che corrano tempi troppo infausti ed avversi alle belle arti. Io faccio voti a Dio acciò faccia risplandere sullo sconvolto globo terraqueo qualche ragio di pace, perché così potrebbesi più agevolmente trovar padrocinio ed incoraggire prestantissimi ministri che ora debbon tutto occupare il loro spirito in sistemi bellicosi,

33 Nuria Soriano Muñoz, «Inventando el pasado, creando la nación: la aportación de Diosdado Caballero», Cuadernos dieciochistas, 14 (2013), págs. 139-140.

34 Masdeu, Poesie di ventidue autori spagnuoli del cinquecento, pág. 34.

35 Sobre la actividad intelectual de Diosdado Caballero, véanse las aportaciones de Elena de LorEnzo Álvarez, «La América censurada del siglo XviII. En torno a las apologías y proyectos de Ramón Diosdado Caballero», América sin nombre, 18 (2013), págs. 114-124.

36 Carta de Raimundo Diosdado Caballero a Giambattista Bodoni de 1793-12-04, ed. Pedro M. Cátedra, en Biblioteca Bodoni [http://bibliotecabodoni.net/carta/1793-12-04-diosdado-bodoni (Consulta: 18/04/2018]. 
senza poter dare un sol pensiere a' professori delle arti mansuete di pace, ed ai' coltivatori della amena letteratura ${ }^{37}$.

Italia casi tuvo el privilegio producir la primera reedición del Bernardo, a la manera de la stampa bodoniana. Y no es poco, dado que en España no se reeditó el texto hasta el año de 1808. La nación aceptó con cierto retraso y lentitud el valor del poema heroico, pero, al menos, antes del reconocimiento general, hubo pequeños indicios que nos indican una progresiva consideración del texto, todo gracias, desde luego, al impulso que se dio desde Italia. Considero de vital importancia comprender la carga simbólica del proyecto de reedición del Bernardo, dado que, gracias a este, España — país muchas veces considerado como «la nación sin épica»— ofreció un poema heroico, cuya calidad y virtudes hacían posible la comparación y enfrentamiento con un texto épico del parangón de La Gerusalemme de Tasso.

\section{La literatura a servicio de la historia}

El Bernardo de Balbuena gozó de impulso en Italia gracias a este círculo erudito que tanto beneficio trajo a la defensa de nuestras letras. Mientras, en España, las noticias del proyecto no resonaron en el círculo de intelectuales, quienes perseguían otras motivaciones para el texto y la figura de Bernardo del Carpio.

En la España de la segunda mitad del XviII el debate sobre qué mitos nacionales debían conformar la historia colectiva permanecía a la vez candente y en convivencia con otros temas relacionados con el gusto poético y las reglas de composición. En este marco, la figura de Bernardo del Carpio generó un interés entre los intelectuales de la época, y su relación con el poema de Balbuena se disipa entre la propuesta de un poema épico de corte nacionalista junto a la propuesta de un canon de poetas áureos.

El debate historiográfico sobre el mito carpiano es una cuestión que siempre ha despertado el interés por algún hombre de letras de nuestra historia literaria. El mismo autor del Bernardo se permite reflexionar sobre la existencia del personaje y su empleo como referente moral y nacional en su epopeya.

En el momento en que estos elementos se recuperaban y analizaban, el erudito Juan de Ferreras dejaba reflejado en algún lugar de los 16 volúmenes

${ }_{37}$ Carta de Giambattista Bodoni a Raimundo Diosdado Caballero de 1793-12-00, ed. Pedro M. Cátedra, en Biblioteca Bodoni [http://bibliotecabodoni.net/carta/1793-12-00-bodoni-diosdado (Consulta: 18/04/2018)]. 
que completan su obra Synopsis histórica chronologica de España (1700-1727) que el héroe castellano jamás existió ${ }^{38}$. Ferreras se apoya en la falta de material sobre el que basar este personaje como histórico y acude a las variantes de la historia en las que Bernardo pasa de ser un héroe castellano hasta sobrino del mismo Carlomagno ${ }^{39}$. Contra este juicio clama Feijoo en el tomo IV de su Teatro crítico universal (1730) alegando otros personajes históricos de cuya existencia tenemos distintas versiones y no por ello se condenan a no haber existido (TC, IV, 13, § XVII-XIX, 56-64). El erudito aprovecha para tratar la cuestión carpiana desde la razón, tachando a Ferreras de emplear un método en el que la sistematicidad brilla por su ausencia, por seguir y dar crédito antes a la crítica francesa que al estudio de las fuentes. En Sarmiento, Memorias para la historia de la poesía y poetas españoles, la figura del héroe queda relegada a un mero personaje de romances ${ }^{40}$, sin entrar en el debate historiográfico ni en la carga de identidad que conlleva del mito, solo en el contenido moralizante. Será en la colección de historias de Hilario Santos Alonso y Manuel José Martín (1767-1780) donde vuelva a aparecer el personaje bajo el telón del rigor histórico y la veracidad literaria, como indica Víctor Infantes, «con el fin de fingir lo menos posible la historia» ${ }^{41}$, principios recogidos en un título como Historia fiel y verdadera del valiente Bernardo del Carpio: sacada con toda fidelidad de los célebres historiadores de España, el padre Mariana, Morales, Berganza y otros muchos autores verídicos y graves. En contraste, otra obra histórica Historia verdadera de la vida y valerosos hechos de Bernardo del Carpio, sobrino del rey don Alfonso el Casto, publicada en Sevilla por Nicolás Vázquez toma de las comedias áureas dedicadas al personaje su materia literaria ${ }^{42}$.

La figura de Bernardo del Carpio se ve alejada, por el momento, de la poesía épica, siendo una figura más próxima al debate sobre su existencia, la documentación historiográfica, y la presencia en el imaginario nacional a partir del romancero.

38 Juan de Ferreras, Synopsis historica chronologica de España. Parte primera, Madrid, Francisco de Villa-Diego, 1700, págs. 96-97

39 A lo largo del estudio de Mercè BoIXAReu y Robin Lefere (coords.), La historia de Francia en la literatura española: amenaza o modelo, Madrid, Castalia, 2009, aparece sistematizada la presencia de Bernardo del Carpio en la literatura española.

40 Martín Sarmiento, Memorias para la historia de la poesía y poetas españoles, Ibarra, Madrid, 1775 (escrito en 1745), págs. 275-280.

${ }^{41}$ Víctor Infantes, «Fingir la historia. La Colección de varias historias de Hilario Santos Alonso y Manuel Joseph Martín (1767-1780), un testimonio editorial de re(escritura) literaria», Historias fingidas, 2 (2014), págs. 25-48.

42 Alma Mejía González, «De la comedia áurea al pliego suelto narrativo: el caso de Bernardo del Carpio», en Actas del XIV Congreso de la Asociación Internacional de Hispanistas. New York, 16-21 de julio de 2001, Delaware, Juan de la Cuesta, 2004, vol. II, pág. 384. 
Este aparente desinterés por la épica medieval castellana queda revelado también en la pobre acogida que tuvo la primera edición del Cid (1779) de Tomás Antonio Sánchez. Como indica Galván ${ }^{43}$, el gusto neoclásico apremiaba el estilo elevado, en contraste con la «rusticidad» del habla antigua. Esto apenas generó una mera apreciación por su interés histórico y una burla de Forner contra la práctica de este editor, al que consideraba «amigo de sacudir el polvo a los libros que le placen y le desplacen; tremendo glosador» ${ }^{44}$.

Este testimonio de recepción abre una brecha en el marco de interpretación del mito, cuya presencia se justifica por elementos ajenos a la poesía épica, contrariamente a como cabría esperar. En términos precisos, fuera de los debates historiográficos, la pervivencia del mito carpiano se debe a la transmisión del teatro del Siglo de Oro, en el cual este personaje fue protagonista de algunas comedias de autores de la talla de Lope de Vega o Juan de la Cueva ${ }^{45}$. En consecuencia, el mito pervive bajo la connotación moralizante empleada en el género dramático y en los romances eruditos.

Considerando la idea que se tenía por esos años del personaje de Bernardo del Carpio, la formulación de la cuestión debe por tanto reorientarse hacia qué fue lo que motivó la recuperación del poema de Balbuena y por qué este es elegido el texto representativo de nuestro género épico. En la documentación sobre el personaje, bien como referente histórico o como mito fundacional de Castilla, héroe moral de romances o personaje deformado por el género caballeresco, identificamos dos marcos de interpretación: el valor literario, por un lado, y la utilidad política del mito, por otro. Esta última es la que ofrece la épica culta, es el mito relegado a la identidad y al contenido político de su materia.

Junto a las alusiones al personaje de Bernardo del Carpio, Balbuena era mencionado como uno de los autores de referencia antes y después de la labor de Masdeu. Sin llegar a abordar todavía el valor político e histórico del poema, identificamos otra rama de la crítica al atender al planto de Moratín en su Lección poética (1782) contra los vicios en la poesía épica, en particular:

Allí se ven nuestros abuelos godos, sus costumbres y heroica bizarría

43 Luis Galván, El Poema del Cid en España, 1779-1936: recepción, mediación, historia de la filología, Pamplona, Eunsa, 2001, págs. 41 y 48.

44 En respuesta a la Carta de Paracuellos (1789), de Tomás Antonio Sánchez, donde pretendía echar burlas contra la Oración apologética. Visto en François Lopez, Juan Pablo Forner y la crisis de la conciencia española en el siglo XVIII, pág. 463.

45 Mejía GonzÁLEz, «De la comedia áurea al pliego suelto narrativo: el caso de Bernardo del Carpio», págs. 383-387. 
desfiguradas de diversos modos.

Todo es jactancia y necia valentía,

todos jaques, ninguno caballero,

como mi patria los miró algún día.

No es más que un mentecato pendenciero

el gran Cortés y el hijo de Jimena

un baladrón de charpas y jifero. ${ }^{46}$

Un fanfarrón de postura y armazón poco caballerescos, esta es la idea del Bernardo del Carpio de la poesía épica que recibe el juicio de Leandro Fernández de Moratín, muy parecida a la desazón que presentaba Quevedo en su burla poética Poema heroico de las necedades y locuras de Orlando el Enamorado dirigido al hombre más maldito del mundo $(1635)^{47}$.

En el tomo tercero del Origen, progresos y estado actual de toda literatura, del erudito y jesuita expulsado Juan Andrés, menciona que, si El Bernardo estuviese despojado de algunos elementos propios de aquel estilo y lejanos al gusto contemporáneo, podría ser considerados entre los mejores poemas épicos escritos $^{48}$. Madramany y Carbonell, traductor y glosador del Arte Poética de Boileau, menciona a Balbuena en el trascurso del canto III, dedicado a la poesía épica, considerando al autor el más distinguido de la epopeya hispánica ${ }^{49}$. Por su parte, Moratín vuelve a cargar contra la épica culta en La derrota de los pedantes (1789), donde afirma «Bernardo de Valbuena y el buen Ercilla conducían a Clío desmayada, casi moribunda, el peinado deshecho, el brial roto y las narices hinchadas y sangrientas» ${ }^{50}$.

Dependiendo del referente del que se parta, existen dos maneras de entender el personaje de Bernardo del Carpio. Según las comedias y el género caballeresco, que deforman a los personajes, o conforme a la épica áurea, la

46 Leandro Fernández de Moratín, Lección poética. Sátira contra los vicios introducidos en la poesía castellana impresa por la Real Academia Española, por ser entre las presentadas la que más se acerca a la que ganó el premio, Madrid, Ibarra, 1782, pág. 24. Véase edición crítica en Leandro Fernández de Moratín, Poesías completas, ed. de Jesús Pérez Magallón, Barcelona, Quaderns Crema, 1994.

47 «Canto los disparates, las locuras / los furores de Orlando enamorado, /cuando el seso y razón le dejó a escuras/el dios enjerto en diablo y en pecado; / y las desventuradas aventuras / de Ferragut, guerrero endemoniado; / los embustes de Angélica y su amante, / niña buscona y doncellita andante; / hembra por quien pasó tanta borrasca», en Francisco de Quevedo, Obra poética, ed. de José Manuel Blecua, Madrid, Castalia, 1971, t. III, pág. 411.

48 Juan AndRÉs, Origen, progresos y estado actual de toda la literatura, Madrid, Sancha, 1785, t. III, pág. 278.

49 Nicolás Bolleau Despreau, El Arte Poética. Traducida del verso francés al castellano por don Juan Bautista Madramany y Carbonell, Valencia, Joseph y Tomás de Orga,1787, pág. 64.

50 Leandro Fernández de Moratín, La derrota de los pedantes, Madrid, Benito Cano, 1789, págs. 10-11. 
cual, aunque tediosa y ajena al gusto del momento, aporta sucesos y elementos nacionales muy bien avenidos para los proyectos apologéticos de esos años y, aún mejor, para avivar el sentimiento anti-francés.

De lo relatado con anterioridad se deduce una clara relación causa-efecto que ejercieron los proyectos del jesuita con la recuperación de la figura de Balbuena y su epopeya. Dejando el camino abierto a futuras investigaciones sobre el desarrollo de la épica durante el siglo ilustrado, relataré las menciones al poema que se dieron a partir de estas actividades, tan numerosas y seguidas, que no me hacen sospechar de un origen distinto.

Antes de nada, no debemos entender por «menciones» comentarios positivos o alabanzas al poema: para este propósito cualquier comentario es válido para relatar la transmisión. Digo esto para que no resulte extraño que la primera mención a Balbuena sea para tomarle como ejemplo de mala praxis. Los críticos de este autor conocen sus virtudes y sus defectos y, en lo último, fue Pedro de Estala el que, en 1794, en su edición del Pluto de Aristófanes, plasmó su referencia a Balbuena en la práctica de las bellas artes donde se «necesita algo más que el conocimiento teórico de sus reglas» ${ }^{51}$. Y ahí va la dura crítica, y no le faltaba razón, ya que el lector del Bernardo es muy consciente de la pesadez del texto, no solo por tratarse de épica culta per se, sino por el barroquismo del autor:

Valbuena puso a su Bernardo un prólogo juicioso sobre el poema épico, y seguidamente nos presenta una fábula monstruosa, en que el héroe se pierde en tanta multitud de episodios importunos ${ }^{52}$.

Afortunadamente, el comentario de Estala no tuvo mayor repercusión que el reconocimiento de cierto ocultismo y desorden en el estilo y episodios del Bernardo. Este sí se empleó, sin embargo, para un gran proyecto con autoría de Juan Pablo Forner, el poema heroico titulado La Paz dedicado a Godoy, impreso en 1796 pero de fecha de composición indeterminada. Conocemos la relación del poeta con El Bernardo gracias al Elogio de María Sotelo ${ }^{53}$, lugar en el que

51 Aristófanes, El Pluto, comedia de Aristófanes, traducida del griego en verso castellano, con un discurso preliminar sobre la comedia antigua y moderna por don Pedro Estala, Madrid, Sancha, 1794, pág. 36.

52 Aristófanes, El Pluto, pág. 36.

53 La relación del poema de Forner con el de Balbuena queda recogida también por L. A. de Cueto en la BAE, Poetas líricos del siglo XVIII, tomo II, Madrid, Rivadeneyra, 1871, págs. 289-293, lugar en el que se vuelve a publicar el Elogio de Sotelo. LopEz, dedica un apartado de su monografía a describir la relación 
relata dos años después de la publicación del poema, que «mejoró notablemente su carácter, para lo cual estuvo templando muchos días con la continua lección de Bernardo de Valbuena» ${ }^{54}$. Como indicó Sotelo, Forner «copió las bellezas de Valbuena» ${ }^{55}$ como autor de referencia entre el resto de autores de épica culta y, además, como indican críticos como Real de la Riva ${ }^{56}$, es una constante en la mayoría de autores de la escuela salmantina.

Por último, a modo de colofón del siglo, el letrado Alberto Lista y Aragón leyó su discurso Examen a Balbuena en la Academia de Letras Humanas el 25 de septiembre de 1799. Analizó la recepción previa del Bernardo, con atención a los autores mencionados, recalcó la falta de noticias en la "provincia del erudito Parnasista ${ }^{57}$ e identificó la causa del poco éxito del poema en su excesivo y oculto carácter moralista. Sin embargo, como detalle de mayor relevancia, dirijo mi atención a la parte en la que enfrenta la figura de Ariosto a la de Balbuena, claro signo de emulación al discurso de Masdeu: «Olvidábaseme decir que en lo que únicamente excede el primero con notables ventajas á nuestro poeta es en la multitud, extensión y viveza de los cuadros obscenos, género para que parece haber nacido Ariosto» ${ }^{58}$.

Tras este trabajo, queda estudiada la relación que efectivamente podemos establecer entre la labor humanista de Masdeu con la posterior recepción de Balbuena. Se ha podido comprobar cómo las ideas originales del jesuita hacen presencia en el resto de autores que, de una manera u otra, mencionan al poeta. Sea por el verdadero valor de su Parnaso o el proponer un poema épico a la altura del de Tasso, se nos ha revelado una línea de acción humanista que tuvo consecuencias directas a finales de nuestro siglo XVIII entre España e Italia.

La escenografía de nuestro estudio queda ya alejada del rapporto EspañaItalia, y pasa a concentrarse en la trayectoria editorial del texto en territorio nacional. Los trabajos y menciones al Bernardo anteriormente examinadas dieron un nuevo impulso al texto, siendo el inicio del siglo receptor y amplificador de esta tendencia.

de Forner y Godoy, al que está dedicado el poema, en Juan Pablo Forner y la crisis de la conciencia española en el siglo XVIII, págs. 549-550.

54 Joaquín María Sotelo, Elogio del Sr. D. Juan Pablo Forner, fiscal del real y supremo Consejo de Castilla y presidente de la Real Academia del derecho español y público de esta corte, leído en la junta general extraordinaria de dicho cuerpo el día 23 de mayo de 1797, Madrid, Cano, 1798, pág. 95-96.

55 Sotelo, Elogio del Sr. D. Juan Pablo Forner, pág. 96.

56 César Real de la Riva, «La escuela poética salmantina del siglo XVIII», Boletín de la Biblioteca de Menéndez Pelayo, xxıv, año XXI, 1 (1948), págs. 321-364.

57 Alberto Lista y Aragón, «Examen de Balbuena», Revista de Ciencias, Literatura y Artes, vol. III (1856), págs. 81-92 y 33-143, pág. 82.

58 Lista y Aragón, «Examen de Balbuena», pág. 142. 
Aun entrados ya en el nuevo siglo, no podemos dejar de mencionar el gran interés de repasar las siguientes ediciones del Bernardo (Sancha, 1808; Quintana, 1833; Eugenio de Ochoa, 1840; BAE, 1851; Gaspar y Roig, 1852) y sus contextos, ya que, en su mayoría, es Quintana el responsable del despertar del interés por dicho poema. Entre 1805 y 1806 se conocían las primeras noticias acerca de la nueva edición del Bernardo, proyecto que llegó a Jovellanos ${ }^{59}$ y Lord Holland, este último por correspondencia directa con el editor ${ }^{60}$.

La mano invisible de Quintana fue la encargada de la preparación del texto presentado en 1808 por el taller de Sancha. Según reza el prólogo, la publicación del poema cumple con hacer «un servicio importante a nuestras letras» ${ }^{61} \mathrm{y}$ colocar a Balbuena dentro del grupo de autores relevantes. El editor insiste en el mal estado del texto impreso en 1624, y dice haber corregido e intervenido en él para hacerlo accesible al público «a cuya utilidad se dedica» ${ }^{62}$. Además de intervenir en el texto, modifica el título original para que la atención se centre solo en el nombre del héroe 'Bernardo', con la continuación, tampoco original, de 'poema heroico'. Este es un aspecto de relevancia ya que por esos años España enfrentaba la invasión napoleónica y declaraba el concepto e identidad nacionales ${ }^{63}$. Y es aún más relevante si se valora la palingénesis del mito de Bernardo del Carpio, mito que pudo resultar extremadamente útil si se utilizaba como panfleto anti-francés. Deducimos, por tanto, que no fue ninguna casualidad que Masdeu propusiese precisamente este texto que tan bien se adaptaba a la época en la que Francia era para España algo nada parecido a una nación aliada. Los siguientes proyectos de reimpresión del texto reciben el trato del Quintana moderado (1833), quien en Musa épica recoge los poemas épicos españoles. La aparición del texto de Balbuena en esta colección es un indicio del paulatino asentamiento del poema en la historia literaria ya que, debido a

59 «No conocía al Roncesvalles; pero conozco el Bernardo, que es su verdadero título, obra del obispo Balbuena, que si no es excelente poema, por lo menos tiene excelentísimas octavas. Celebro mucho que se imprima, y le compraré luego que salga», en Gaspar Melchor de Jovellanos, Obras completas, t. IV, Correspondencia, 3. ${ }^{\circ}$, ed. de José Miguel Caso González, Oviedo, Ayuntamiento de Gijón / Instituto Feijoo de Estudios del Siglo XVIII, 1988, pág. 219; Jean-Pierre CLÉMENT recoge el Bernardo de 1624 entre las lecturas del erudito, en Las lecturas de Jovellanos. Ensayo de reconstitución de su biblioteca, Oviedo, Instituto de Estudios Asturianos, 1980, pág. 20.

60 Carta del 8 de diciembre de 1806 de Quintana a Lord Holland, en la que dice: «Se está reimprimiendo el Bernardo de Balbuena baxo mi dirección en la imprenta de Sancha, y no me he olvidado de que prometí enviar a V. un exemplar en el momento que se publique.» en Manuel Moreno Alonso, El miedo a la libertad en España. Ensayos sobre Liberalismo y Nacionalismo, Sevilla, Alfar, 2006, pág. 230.

${ }^{61}$ Bernardo De Balbuena, El Bernardo: poema heroyco, tomo I, Madrid, Sancha, 1808, pág. 4.

62 Bernardo De Balbuena, El Bernardo: poema heroyco, pág. 4.

63 José Luis VILLACAÑAS, «Una idea y escritura de la historia en la conciencia nacional del siglo XVIII» Cuadernos Dieciochistas, 14 (2013), págs. 19-57. 
los momentos de moderación, pierde el valor de identidad y se aproxima más al de la mera recopilación. Más tarde se publica otra antología de textos bajo la misma línea de Musa épica, en París (1840) por Eugenio de Ochoa. La conversión oficial del texto conocido solo por las élites, a un texto canónico del género épico, se produjo en la nueva edición realizada por la $B A E$ en 1851. En la advertencia preliminar, Cayetano Rosell reconoce así el valor del Bernardo:

No teman, sin embargo, nuestros lectores desalentar en el largo espacio de cuarenta mil versos que comprende este poema. A cada paso encontrarán bellezas donde recrear su vista, alicientes que les hagan olvidar el fastidio de tal o cual pasaje, y sin sentirlo, proseguir embebecidos en su lectura, que este es el privilegio de los talentos superiores. ${ }^{64}$

El Bernardo ya no se es tratado como una reliquia ni como un poema objeto del nacionalismo, sino como un texto patrimonial, capaz de llevar el estandarte de la poesía épica junto a Ercilla. Un año más tarde, el poema se emplea para la divulgación popular gracias a Gaspar y Roig (1852), que incluye grabados de las escenas más relevantes de la obra.

\section{Notas finales}

Como culmen, aunque no fin, de la transmisión y recuperación del Bernardo localizamos estas ediciones cuyo objetivo fue el de acercar paulatinamente a los eruditos y al público los grandes autores nacionales revestidos como símbolos del talento cultural. Por lo que esta labor, iniciada en parte en manos del círculo de jesuitas expulsos durante la segunda mitad del siglo ilustrado, cumple con el proyecto que anunciábamos como el realmente beneficioso para la imagen de España frente a Europa. La versatilidad del poema está reconocida en su adaptación al gusto de la época y al contexto histórico. La respuesta a la cuestión de por qué se recupera El Bernardo se localiza más en su utilidad histórica que en su riqueza literaria. Su estilo ha sido más criticado que alabado, más señalado como poema con imperfecciones que como ejemplo de un estilo limpio y elegante. Sin embargo, permanece la cuestión de qué es considerado un buen poema épico. En nuestro caso de estudio, vemos cómo se pierde el rigor

64 Biblioteca de Autores Españoles desde la Formación del Lenguaje hasta nuestros días. Poemas épicos. Colección dispuesta y revisada con notas biográficas y una advertencia preliminar, Madrid, Cayetano Rosell, Rivadeneyra, 1851, pág. 4 
clasicista y se acepta una obra, la cual no es reconocida por su gran estilo, sino por su gran aportación a la historia e identidad nacionales.

Más allá, nuestro relato ha tratado de asentar las bases para un aspecto que contiene otras implicaciones. Las formas de lectura y la predisposición de los jesuitas por el género épico revelan una noción muy especializada de los géneros literarios y, en especial, de la epopeya. Este camino de investigación cuenta ya con el primer acercamiento de Sánchez Manzano ${ }^{65}$, quien identifica y analiza una doctrina jesuítica para el género épico. Probablemente debamos considerar la teoría de los géneros literarios como doctrinas que surgen siguiendo también los intereses de una especie de arcadia exclusiva y no solo según las voces de tratadistas en función a sus escuelas. La Compañía, en su hermético saber y proceder, favoreció de alguna manera ideas teóricas únicas, influidas por las corrientes, pero intrínsecamente genuinas y cerradas. Su origen podría estar en el poema heroico sobre la vida de Ignacio de Loyola (Madrid, 1666) del ignaciano Hernando Domínguez Camargo (1606-1659) y su continuidad en el Compendio del arte poética (1757) de Antonio Burriel y la Eneida apostólica o Margileida de Larrañaga (México, 1788), teniendo como senso común esta poética jesuítica. El análisis de estos textos queda abierto para futuras investigaciones que darán luz sobre la cuestión de si los jesuitas formularon una teoría literaria propia y en qué medida convivió con el resto de poéticas europeas.

65 María Asunción Sánchez Manzano, «A Jesuit Poetic Doctrine: Mambrun’s Dissertatio de epico carmine», Evphrosyne. Revista de Filologia clásica, vol. xLV (2017), págs. 381-394. 